\title{
Cytosolic NADPH balancing in Penicillium chrysogenum cultivated on mixtures of glucose and ethanol
}

\author{
Zheng Zhao • Karel Kuijvenhoven • Walter M. van Gulik • \\ Joseph J. Heijnen • Wouter A. van Winden • \\ Peter J. T. Verheijen
}

Received: 1 July 2010 / Revised: 9 August 2010 / Accepted: 16 August 2010 / Published online: 31 August 2010

(C) The Author(s) 2010. This article is published with open access at Springerlink.com

\begin{abstract}
The in vivo flux through the oxidative branch of the pentose phosphate pathway (oxPPP) in Penicillium chrysogenum was determined during growth in glucose/ethanol carbon-limited chemostat cultures, at the same growth rate. Non-stationary ${ }^{13} \mathrm{C}$ flux analysis was used to measure the oxPPP flux. A nearly constant oxPPP flux was found for all glucose/ethanol ratios studied. This indicates that the cytosolic NADPH supply is independent of the amount of assimilated ethanol. The cofactor assignment in the model of van Gulik et al. (Biotechnol Bioeng 68(6):602-618, 2000) was supported using the published genome annotation of $P$. chrysogenum. Metabolic flux analysis showed that NADPH requirements in the cytosol remain nearly the same in these experiments due to constant biomass growth. Based on the cytosolic NADPH balance, it is known that the cytosolic aldehyde dehydrogenase in $P$. chrysogenum is $\mathrm{NAD}^{+}$dependent. Metabolic modeling shows that changing the $\mathrm{NAD}^{+}$-aldehyde dehydrogenase to $\mathrm{NADP}^{+}$-aldehyde dehydrogenase can increase the penicillin yield on substrate.
\end{abstract}

Z. Zhao $(\bowtie) \cdot$ K. Kuijvenhoven · W. M. van Gulik ·

J. J. Heijnen · P. J. T. Verheijen

Department of Biotechnology,

Kluyver Centre for Genomics of Industrial Fermentation,

Delft University of Technology,

Julianalaan 67, 2628BC, Delft, The Netherlands

e-mail: z.zhao@tudelft.nl

P. J. T. Verheijen

e-mail: p.j.t.verheijen@tudelft.nl

W. A. van Winden

DSM Anti-Infectives, A. Fleminglaan 1,

2613AX, Delft, The Netherlands
Keywords Isotopic non-stationary ${ }^{13} \mathrm{C}$ flux analysis . Metabolic flux ratio analysis $\cdot$ Pentose phosphate pathway $\cdot$ Metabolic engineering . NADPH metabolism

\section{Introduction}

Using classical strain improvement programs, the industrial Penicillium chrysogenum strain has been improved for $\beta$-lactam production by more than 1,000fold (Thykaer and Nielsen 2003). Rational metabolic engineering is the next step, allowing further improvements and addressing the relationship between production pathways and the central metabolism (Nasution et al. 2008).

The biosynthesis pathways of the penicillin carbon precursors cysteine and valine require large amounts of NADPH (Kleijn et al. 2006; Lee and Hwang 2003; Blombach et al. 2008). A strong positive correlation between intracellular NADPH demand and the penicillin production rate was calculated by metabolic flux analysis (Henriksen et al. 1996; van Gulik et al. 2000). It has also been known that most of the NADPH demand incurred by penicillin production resides in the cytosol (Evers et al. 2004; Kleijn et al. 2007). Due to its role in NADPH metabolism, the flux through the oxidative branch of the pentose phosphate pathway (oxPPP) was known to be the limiting factor in the production of several amino acids (Wittmann and Heinzle 2002; Georgi et al. 2005; Kabus et al. 2007). Investigation of the cytosolic NADPH sources and sinks can therefore provide further insights into the process and identify potential NADPH-related metabolic engineering targets. 
The oxidative branch of the pentose phosphate pathway is the main cytosolic NADPH source. Study of the oxPPP flux is therefore relevant to rational strain improvement. The source of NADPH has been shown to vary with the carbon source (Minard and McAlisterHenn 2005). An interesting approach used to manipulate the NADPH source is to use mixed substrate, e.g., glucose/ethanol, because aldehyde dehydrogenase (ALD6 of Saccharomyces cerevisiae) was shown to be an important cytosolic NADPH source for fungi (Grabowska and Chelstowska 2003; Bro et al. 2004). Similarly, van Gulik et al. (2000) assumed that ethanol oxidation provides NADPH in $P$. chrysogenum based on the results described by Bruinenberg et al. (1983) on Candida utilis. Mixing ethanol with glucose can therefore potentially shift the load of $\mathrm{NADP}^{+}$reduction from oxPPP to ethanol uptake.

The metabolic model of van Gulik et al. (2000) contained ten cytosolic metabolic reactions that consume cytosolic NADPH for amino acid, fatty acid synthesis, or the reduction of sulfur. Table 1 lists all of the cytosolic NADPH-consuming reactions/pathways in the $P$. chrysogenum metabolic model developed by van Gulik et al. (2000). Based on the published annotation of the genomic sequences (van den Berg et al. 2008), the putative enzymes that catalyzes these redox reactions can be now assigned. This annotation information supports most of the cofactor assignments in the van Gulik et al. (2000) model (compare Tables 1 and 2), except the histidine synthesis pathway r11.32.
This pathway of r11.32 lumped the reaction from $\alpha$-5-phosphoribosylpyrophosphate (PRPP) to histidine. Two $\mathrm{NAD}^{+}$and one NADPH were required in this lumped pathway(van Gulik et al. 2000). However, the only redox reaction in this pathway is the oxidation from histidinol to histidine (Stepansky and Leustek 2006), which costs two $\mathrm{NAD}^{+}$without NADPH consumption. In addition, the pyrroline-5-carboxylate reductase in the proline synthesis pathway (r11.3) also showed activity toward both NADH and NADPH (Rossi et al. 1977).

Recently, the isotopic non-stationary gluconate tracer method (Zhao et al. 2008) was proved to be suitable for the measurement of the oxPPP flux without long-term cultivation (on the order of several residence times). In addition, the method requires neither assumptions on network reversibility nor knowledge of amino acid biosynthesis routes. The latter feature makes the accuracy of this method independent of the accuracy of the biomass composition data. These features made this method appropriate for quantifying the oxPPP flux of $P$. chrysogenum cultures grown on different mixed glucose/ethanol substrates.

To investigate the cytosolic NADPH metabolism of $P$. chrysogenum, the oxPPP flux was measured using the isotopic non-stationary gluconate tracer method. This work reports the results obtained from chemostat cultures grown on different mixed glucose/ethanol substrate mixtures at the same growth rate. This provides further insights for the penicillin production.

Table 1 Cytosolic NADPH-consuming reactions in the metabolic model of P. chrysogenum (van Gulik et al. 2000)

\begin{tabular}{|c|c|c|}
\hline Name & Reaction & Cofactor \\
\hline $\mathrm{r} 11.1$ & 1 aKG:cyt +1 H:cyt + 1 NADPH:cyt +1 NH4:cyt $\Rightarrow 1$ glu:cyt +1 H2O:cyt +1 NADP:cyt & NADPH \\
\hline $\mathrm{r} 16.3$ & $\begin{array}{l}9 \text { AcCoA:cyt + } 8 \text { ATP:cyt }+8 \text { H:cyt }+16 \text { NADPH:cyt } \Rightarrow 8 \text { ADP:cyt }+8 \text { HCoA:cyt }+ \\
16 \text { NADP:cyt }+8 \text { Pi:cyt }+1 \text { steaCoA:cyt }\end{array}$ & NADPH \\
\hline r11.18 & 1 asp:cyt +1 ATP:cyt +2 H:cyt +2 NADPH:cyt $\Rightarrow 1$ ADP:cyt +1 homser:cyt +2 NADP:cyt +1 Pi:cyt & NADPH \\
\hline r11.12 & $1 \mathrm{H}: c y t+4$ NADPH:cyt + 1 PAPS:cyt $\Rightarrow 1$ ADP:cyt +3 H2O:cyt + 1 H2S:cyt + 4 NADP:cyt & NADPH \\
\hline r11.3 & $\begin{array}{l}1 \text { ATP:cyt }+1 \text { glu:cyt }+2 \text { H:cyt }+2 \text { NADPH:cyt } \Rightarrow 1 \text { ADP:cyt }+1 \text { H2O:cyt }+2 \text { NADP:cyt }+ \\
1 \text { Pi:cyt }+1 \text { pro:cyt }\end{array}$ & NADPH \\
\hline $\mathrm{r} 11.8$ & $\begin{array}{l}1 \text { aAd:cyt }+2 \text { ATP:cyt }+1 \text { glu:cyt }+1 \text { H2O:cyt }+1 \text { NAD:cyt }+2 \text { NADPH:cyt } \Rightarrow 2 \text { ADP:cyt }+ \\
1 \text { aKG:cyt }+1 \text { H:cyt }+1 \text { lys:cyt }+1 \text { NADH:cyt }+2 \text { NADP:cyt }+2 \text { Pi:cyt }\end{array}$ & NADPH \\
\hline r11.27 & 1 ATP:cyt +1 E4P:cyt +1 NADPH:cyt +2 PEP:cyt $\Rightarrow 1$ ADP:cyt +1 chor:cyt +1 NADP:cyt +4 Pi:cyt & NADPH \\
\hline r16.13 & 3 AcCoA:cyt +1 H:cyt +1 H2O:cyt +2 NADPH:cyt $\Rightarrow 3$ HCoA:cyt +1 meva:cyt +2 NADP:cyt & NADPH \\
\hline r11.32 & $\begin{array}{l}3 \text { ATP:cyt }+1 \text { CO2:cyt }+1 \text { gln:cyt }+3 \text { H2O:cyt }+2 \text { NAD:cyt }+1 \text { NADPH:cyt }+1 \text { NH4:cyt }+1 \text { PRPP:cyt } \Rightarrow \\
3 \text { ADP:cyt }+1 \text { aKG:cyt }+8 \text { H:cyt }+1 \text { his:cyt }+2 \text { NADH:cyt }+1 \text { NADP:cyt }+6 \text { Pi:cyt }\end{array}$ & $\begin{array}{l}\text { NADPH }+ \\
\text { NAD }^{+}\end{array}$ \\
\hline r16.14 & $\begin{array}{l}18 \text { ATP:cyt }+5 \text { H2O:cyt }+6 \text { meva:cyt }+2 \text { NADPH:cyt }+1 \text { O2:cyt } \Rightarrow 18 \text { ADP:cyt }+6 \text { CO2:cyt }+10 \text { H:cyt }+ \\
1 \text { lano:cyt }+2 \text { NADP:cyt }+18 \text { Pi:cyt }\end{array}$ & NADPH \\
\hline
\end{tabular}

aAd $\alpha$-aminoadipate, $A c C o A$ acetyl coenzyme A, $a K G \alpha$-ketoglutarate, asp aspartate, chor chorismate, cyt cytosol, E4P erythorose-4phosphate, gln glutamine, glu glutamate, $H$ proton, $H C o A$ coenzyme A, his histidine, homser homoserine, lano lanosterol, lys lysine, meva mevalonate, PAPS 3-phosphoadenosine-5-phosphosulfate, PEP phosphoenolpyruvate, Pi orthophosphate, pro proline, $P R P P \alpha$-5-phosphoribosylpyrophosphate, steaCoA stearoyl coenzyme A 
Table 2 Genes for the cytosolic NADPH-consuming reactions in P. chrysogenum based on the genome annotation

\begin{tabular}{|c|c|c|c|c|}
\hline Name & Gene name & Annotated function & Cofactor & Reference \\
\hline $\mathrm{r} 11.1$ & Pc22g17560 & Glutamate dehydrogenase gdhA & NADPH & $\begin{array}{l}\text { Díez et al. (1999), Harris et al. (2006), } \\
\text { Thykaer et al. (2008) }\end{array}$ \\
\hline $\mathrm{r} 16.3$ & Pc14g00740 & Fatty-acyl-CoA synthase beta chain fas1p & NADPH & Wakil et al. (1983) \\
\hline r11.18 & Pc20g02910 & Aspartate-semialdehyde dehydrogenase & NADPH & Robichon-Szulmajster et al. (1966) \\
\hline r11.18 & Pc13g08990 & Homoserine dehydrogenase & NADPH & Yamaki et al. (1990) \\
\hline r11.12 & Pc12g08580 & Sulfite reductase Met10 & NADPH & Yoshimoto and Sato (1968) \\
\hline $\mathrm{r} 11.3$ & Pc13g05550 & Hypothetical protein ncu01412.1 $1^{\mathrm{a}}$ & NADPH & Baich (1971), Tomenchok and Brandriss (1987) \\
\hline $\mathrm{r} 11.3$ & Pc12g13680 & Pyrroline-5-carboxylate reductase ProC & $\mathrm{NAD}(\mathrm{P}) \mathrm{H}$ & Rossi et al. (1977) \\
\hline $\mathrm{r} 11.8$ & Pc22g06310 & L-aminoadipate-semialdehyde dehydrogenase & NADPH & $\begin{array}{l}\text { Casqueiro et al. (1998), Zabriskie and Jackson } \\
\text { (2000), Hijarrubia et al. (2001) }\end{array}$ \\
\hline $\mathrm{r} 11.8$ & Pc22g05800 & Saccharopine reductase Lys7 & NADPH & Jones and Broquist (1966), Esmahan et al. (1994) \\
\hline $\mathrm{r} 11.27$ & Pc16g12160 & Pentafunctional enzyme aroM ${ }^{\mathrm{b}}$ & NADPH & Duncan et al. (1988) \\
\hline r16.13 & Pc18g05230 & Hydroxymethylglutaryl-CoA reductase & NADPH & Qureshi et al. (1976) \\
\hline r11.32 & Pc16g14140 & Histidinol dehydrogenase his-3 & $\mathrm{NAD}^{+}$ & Creaser and Varela-Torres (1971) \\
\hline r16.14 & Pc21g13930 & Squalene synthase ERG9 & NADPH & Qureshi et al. (1973) \\
\hline
\end{tabular}

${ }^{a}$ Homology with Pro2 of S. cerevisiae ( $\gamma$-glutamyl phosphate reductase)

bShikimate dehydrogenase

A potential metabolic engineering target for altering NADPH metabolism based on metabolic flux analysis is discussed.

\section{Materials and methods}

Strain

A high-yielding $P$. chrysogenum strain (DS17690) was donated by DSM Anti-Infectives (Delft, The Netherlands).

Media and medium preparation

Three chemically defined chemostat media were used to study the metabolism of $P$. chrysogenum on mixed glucose/ethanol substrate at (C mole ethanol)/(total carbon) fraction of $0,0.15$, and $0.48 \mathrm{Cmol} / \mathrm{Cmol}$ (mediums 1a, 1b, 1c) at constant total carbon substrate concentration $0.5 \mathrm{Cmol} / \mathrm{L}$. The composition of medium 1a was $15.68 \mathrm{~g} / \mathrm{L}$ glucose $\cdot \mathrm{H}_{2} \mathrm{O}, 0.74 \mathrm{~g} / \mathrm{L}$ glucono- $\delta$ lactone, $0.675 \mathrm{~g} / \mathrm{L}$ phenylacetic acid (PAA), $0.8 \mathrm{~g} / \mathrm{L}$ $\mathrm{KH}_{2} \mathrm{PO}_{4}, 5 \mathrm{~g} / \mathrm{L}\left(\mathrm{NH}_{4}\right)_{2} \mathrm{SO}_{4}, 0.5 \mathrm{~g} / \mathrm{L} \quad \mathrm{MgSO}_{4} \cdot \mathrm{H}_{2} \mathrm{O}$, and $2 \mathrm{~mL} / \mathrm{L}$ trace element solution. The trace element solution contained $75 \mathrm{~g} / \mathrm{L} \mathrm{Na} \mathrm{Na}_{2}$-EDTA. $2 \mathrm{H}_{2} \mathrm{O}$, $2.5 \mathrm{~g} / \mathrm{L} \quad \mathrm{CuSO}_{4} \cdot 5 \mathrm{H}_{2} \mathrm{O}, 10 \mathrm{~g} / \mathrm{L} \mathrm{ZnSO}_{4} \cdot 7 \mathrm{H}_{2} \mathrm{O}, 10 \mathrm{~g} / \mathrm{L}$ $\mathrm{MnSO}_{4} \cdot \mathrm{H}_{2} \mathrm{O}, 20 \mathrm{~g} / \mathrm{L} \quad \mathrm{FeSO}_{4} \cdot 7 \mathrm{H}_{2} \mathrm{O}$, and $2.5 \mathrm{~g} / \mathrm{L}$ $\mathrm{CaCl}_{2} \cdot 2 \mathrm{H}_{2} \mathrm{O}$. Mediums $1 \mathrm{~b}$ and $1 \mathrm{c}$ were identical to medium 1a except that the ethanol $\mathrm{C}$ mole fraction was changed to 0.15 and $0.48 \mathrm{Cmol} / \mathrm{Cmol}$ while keeping the molar ratio between glucose and glucono- $\delta$-lactone at 19:1. The labeled medium equivalent to $1 \mathrm{a}, 1 \mathrm{~b}$, and $1 \mathrm{c}$ are called mediums $2 \mathrm{a}, 2 \mathrm{~b}$, and $2 \mathrm{c}$ and were chemically identical to their counterparts except that the glucono- $\delta$-lactone was replaced by the same molar amount of $\left[\mathrm{U}_{-}{ }^{13} \mathrm{C}_{6}\right]$ glucono- $\delta$-lactone (Omicron, South Bend, IN, USA).

Cultivation conditions and labeling experiment

The chemostats were carried out at a dilution rate of $0.06 \mathrm{~h}^{-1}, 25^{\circ} \mathrm{C}, \mathrm{pH} 6.5$, and the working volume was controlled at $600 \mathrm{~mL}$ by an overflow system. After reaching the metabolic steady state from each batch phase after approximately five residence times (about 3 days), the naturally labeled mediums $1 \mathrm{a}, 1 \mathrm{~b}$, and $1 \mathrm{c}$ were replaced by ${ }^{13} \mathrm{C}$ gluconate tracer labeled mediums $2 \mathrm{a}, 2 \mathrm{~b}$, and $2 \mathrm{c}$, respectively, until the end of the isotopic non-stationary labeling experiments (usually $5 \mathrm{~h}$ ). The cost of the labeling material is very limited due to the short period of time and the tracer amount needed.

\section{Sampling and analysis}

To calculate the flux through the oxPPP, it was sufficient to quantify the glucose and gluconate uptake rates and the mass isotopomer distributions (MID) of intracellular glucose-6-phosphate (g6p), 6phosphogluconate (6pg), and gluconate (glnic) (Zhao et al. 2008). Samples for mass isotopomer analysis of intracellular metabolites were taken, processed, and analyzed as described by Zhao et al. (2008). The MID of the intracellular g6p, $6 \mathrm{pg}$, and glnic were measured by LC-MS as described by van Winden et al. (2005), and the MID were calculated as described by Zhao et al. (2008).

The extracellular concentrations of PAA and penicillin-G were analyzed by an isocratic HPLC 
method using a Zorbax ${ }^{\circledR}$ column at $30^{\circ} \mathrm{C}$. Triplicate 5 -mL broth samples were taken daily during the fermentation to determine the dry weight of the biomass. Samples were filtered over pre-weighed glass fiber filters (Pall, East-Hills, NY, USA) and dried at $70^{\circ} \mathrm{C}$ for $24 \mathrm{~h}$ and subsequently weighed.

The enzymatic activity of the aldehyde dehydrogenase (ALDH; EC 1.2.1.3 1.2.1.4, 1.2.1.5) was measured using the same protocol as Harris et al. (2006). The reaction mix contained $100 \mathrm{mM}$ potassium phosphate buffer, $\mathrm{pH}$ 8.0, $15 \mathrm{mM}$ pyrazole, $0.5 \mathrm{mM}$ DTT, $10 \mathrm{mM}$ $\mathrm{KCl}$, and $0.4 \mathrm{mM} \mathrm{NAD}^{+}$or $\mathrm{NADP}^{+}$. The reaction was started with $0.1 \mathrm{mM}$ freshly prepared acetaldehyde. The protein concentration in the cell extract was determined by the method of Lowry et al. (1951). Because the pathway converting ethanol to acetate is linear, the actual in vivo fluxes catalyzed by the ALDH are the same as the ethanol uptake rates (see Table 3). In order to compare the in vivo flux through ALDH with the measured in vitro enzyme activity, unit conversion from flux (millimoles per $\mathrm{C}$ mole per hour) to specific activity (micromoles per milligram per minute) is needed. The averaged biomass $\mathrm{C}$ mole weight $M_{\mathrm{w}}$ is $27.7 \pm 0.5 \mathrm{~g} /(\mathrm{Cmol}$ biomass $)$, ranging from glucose-limited biomass composition to ethanol-limited biomass composition. The extracted protein weight fraction in biomass $f_{\mathrm{pr}}$ is a nearly constant 0.25 , based on the protein determination results (see the "Results" section). Therefore, the unit conversion factor from millimoles per $\mathrm{C}$ mole biomass per hour to micromoles per milligram protein per minute can be calculated as:

$$
\begin{aligned}
1 \frac{\mathrm{mmol}}{(\text { Cmol biomass }) \mathrm{h}} & =\frac{1}{M_{\mathrm{w}} f_{\mathrm{pr}} \times 60} \frac{\mu \mathrm{mol}}{(\mathrm{mg} \text { protein }) \mathrm{min}} \\
& =0.0024 \frac{\mu \mathrm{mol}}{(\mathrm{mg} \text { protein }) \mathrm{min}}
\end{aligned}
$$

The off-gas concentrations of $\mathrm{O}_{2}$ and $\mathrm{CO}_{2}$ were measured on-line (non-dispersive/paramagnetic in- frared Rosemount NGA 2000 gas analyzer, FisherRosemount, Hanau, Germany) and the air flow rate was controlled using a mass flow controller.

Black-box elemental balancing of fermentation data

The variance weighed optimization procedure developed by van der Heijden et al. (1994) was used to test elemental recovery and subsequently to reconcile the measured primary fermentation data, based on elemental balancing; it was also used to calculate the biomassspecific uptake and production rates. The statistical acceptance of the balanced results were evaluated by the $\chi^{2}$-test.

\section{Metabolic flux analysis}

The compartmentalized stoichiometric model of $P$. chrysogenum (van Gulik et al. 2000) was used for the metabolic flux analysis. Dedicated software (SPADit, Nijmegen, The Netherlands) was used for the calculations. The biomass compositions of both the glucoselimited culture and the ethanol-limited culture were taken from van Gulik et al. (2000). The difference between these two compositions were insignificant. Moreover, the cytosolic NADPH demand is quite insensitive to the biomass composition. It was therefore considered that linear interpolation is a sufficient approximation to calculate the biomass composition of the mixed substrate cultures.

\section{Results}

Uptake and production rates

P. chrysogenum was cultivated in three different chemostat experiments at the same dilution rate, using

\begin{tabular}{|c|c|c|c|c|c|c|}
\hline \multirow{2}{*}{$\begin{array}{l}q \text {-rates } \\
\mathrm{mmol} / \mathrm{Cmol} / \mathrm{h}\end{array}$} & \multicolumn{2}{|c|}{$0 \frac{\mathrm{Cmol}}{\mathrm{Cmol}}$ ethanol } & \multicolumn{2}{|c|}{$0.15 \pm 0.02 \frac{\mathrm{Cmol}}{\mathrm{Cmol}}$ ethanol } & \multicolumn{2}{|c|}{$0.48 \pm 0.05 \frac{\mathrm{Cmol}}{\mathrm{Cmol}}$ ethanol } \\
\hline & Measured & Reconciled & Measured & Reconciled & Measured & Reconciled \\
\hline$-q_{\text {ethanol }}$ & 0.00 & 0.00 & $8.79 \pm 0.85$ & $8.36 \pm 0.79$ & $29.9 \pm 4.1$ & $26.7 \pm 2.3$ \\
\hline$-q_{\text {glucose }}$ & $20.8 \pm 2.0$ & $20.1 \pm 1.7$ & $16.6 \pm 1.6$ & $15.3 \pm 1.3$ & $9.36 \pm 0.90$ & $9.29 \pm 0.77$ \\
\hline- qgluconate & $1.01 \pm 0.09$ & $0.99 \pm 0.08$ & $0.85 \pm 0.08$ & $0.81 \pm 0.08$ & $0.47 \pm 0.05$ & $0.47 \pm 0.04$ \\
\hline$-\mathrm{qO}_{2}$ & $46.4 \pm 4.7$ & $45.3 \pm 4.4$ & $41.2 \pm 4.0$ & $42.9 \pm 3.9$ & $59.1 \pm 5.5$ & $59.1 \pm 5.1$ \\
\hline$-\mathrm{q}_{\mathrm{PAA}}^{\mathrm{a}}$ & $0.37 \pm 0.09$ & $0.34 \pm 0.04$ & $0.50 \pm 0.07$ & $0.46 \pm 0.04$ & $0.24 \pm 0.15$ & $0.24 \pm 0.15$ \\
\hline$\mu$ & $61.0 \pm 4.9$ & $60.5 \pm 4.9$ & $61.8 \pm 4.3$ & $61.1 \pm 4.3$ & $62.0 \pm 4.2$ & $61.6 \pm 3.6$ \\
\hline qPen-G & $0.34 \pm 0.04$ & $0.34 \pm 0.04$ & $0.48 \pm 0.04$ & $0.46 \pm 0.04$ & $0.24 \pm 0.14$ & $0.24 \pm 0.10$ \\
\hline $\mathrm{qCO}_{2}$ & $50.0 \pm 4.9$ & $49.6 \pm 4.7$ & $36.9 \pm 3.7$ & $38.8 \pm 3.5$ & $36.4 \pm 3.4$ & $36.2 \pm 3.2$ \\
\hline $\mathrm{q}_{\mathrm{by} \text {-product }}^{\mathrm{b}}$ & $14.2 \pm 1.4$ & $13.9 \pm 1.2$ & $9.46 \pm 0.87$ & $9.48 \pm 0.87$ & $12.4 \pm 2.1$ & $12.3 \pm 1.1$ \\
\hline
\end{tabular}

Table 3 Measured and reconciled steady-state biomass specific $q$-rates

${ }^{\text {a Phenylacetic acid }}$

${ }^{\mathrm{b}}$ Extracellular peptides and polysaccharides determined by total organic carbon analysis 
different glucose/ethanol ratios in the media as described in the "Materials and methods" section. The measured and reconciled uptake and production rates are compared in Table 3. Note that Kleijn et al. (2006) used the residual concentration of the gluconate to show that the added gluconate tracer was completely taken up under carbon limited condition. In all three experiments, good consistency was found between the measured rates and the reconciled rates ( $P$ values ${ }^{1}$ are $89 \%, 54 \%$, and $78 \%$, respectively). It was thus concluded that these data contain no gross measurement errors and that there are no unknown by-products. After the elemental balancing, it was found that the actual ethanol fractions in the three experiments were $0,0.15$, and $0.48 \mathrm{Cmol} / \mathrm{Cmol}$.

In the growth conditions studied, metabolic flux analysis shows that the total cytosolic NADPH demand is nearly constant at a rate of $21 \mathrm{mmol} / \mathrm{Cmol} / \mathrm{h}$, irrespective of the ethanol fraction or the cysteine synthesis route (see Fig. 1). This is to be expected given the constant biomass specific growth rate and nearly constant $q_{\mathrm{P}}$. Figure 1 also shows that the cytosolic NADPH was consumed mostly for the synthesis of amino acids. The cost for the fatty acid synthesis was only $5.5 \mathrm{mmol} / \mathrm{Cmol} / \mathrm{h}$ in our experiments. Note that the production of $1 \mathrm{~mol}$ penicillin-G cost 5-8 mol cytosolic NADPH (Kleijn et al. 2007). Independent of the cysteine synthesis route, the maximum possible NADPH demand for penicillin-G production is less than $25 \%$ of the total. Given that the flux through the histidine synthesis pathway was only $0.16 \mathrm{mmol} / \mathrm{Cmol} / \mathrm{h}$ at the studied growth rate (Fig. 1), the originally false cofactor assignment in this pathway therefore resulted in a very limited influence on the total cytosolic NADPH demand in our experiments. For the same reason, the uncertain cofactor specificities in $\mathrm{r} 11.3(0.74 \pm 0.02 \mathrm{mmol} / \mathrm{Cmol} / \mathrm{h})$ hardly affect the total cytosolic NADPH requirement. In short, the analysis above showed that the stoichiometric model of van Gulik et al. (2000) can make reasonably well estimations on the cytosolic NADPH requirements.

\section{Mass isotopomer distribution dynamics} and oxPPP flux

The MID of intracellular g6p, 6pg, and glnic in the three experiments were measured at timed intervals after switching to the labeled medium. The results

\footnotetext{
$\overline{{ }^{1} \text { At a } P \text { value }} \leq 5 \%$, the validity of the reconciliation is rejected.
}

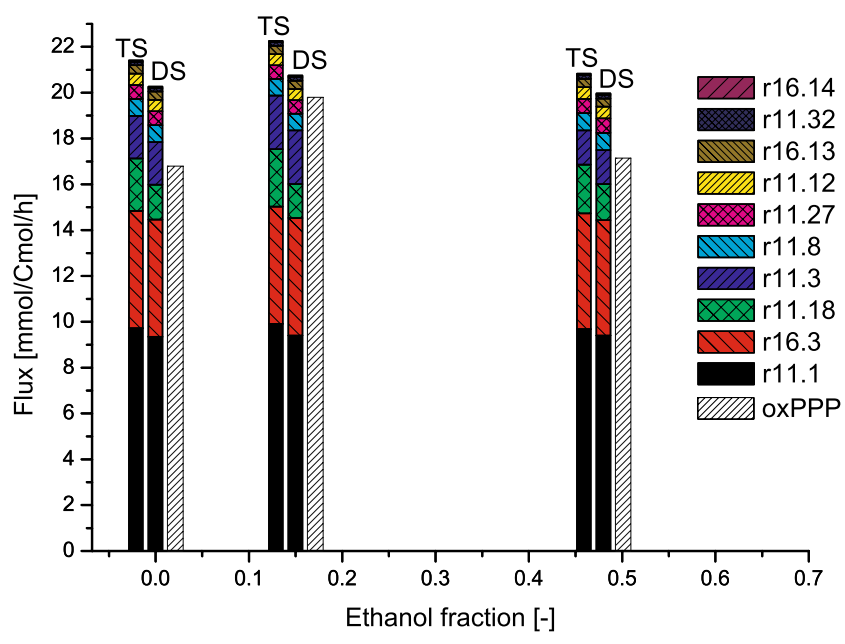

Fig. 1 Cytosolic NADPH fluxes at different ethanol fractions under different assumptions on cysteine synthesis routes. TS The profile of NADPH-consuming reactions under the assumption that cysteine is exclusively synthesized by the transsulfuration pathway. $D S$ The profile of NADPH-consuming reactions under the assumption that cysteine is exclusively synthesized by the direct sulfhydrylation pathway. $0 x P P P$ The NADPH produced by the oxidative branch of PP pathway, based on the flux determined by the ${ }^{13} \mathrm{C}$ flux analysis result. For the meaning of the reaction names other than oxPPP in the legend, please see Table 1

of 6pg carbon MID in all experiments are shown in Fig. 2. In all experiments, the isotopic steady states were reached within $1 \mathrm{~h}$. The uptake rates of the fully labeled gluconate tracer were much lower than the oxPPP flux originated from unlabeled $\mathrm{g} 6 \mathrm{p}$ in all three experiments. As a result, the majority of the $6 \mathrm{pg}$ pools were unlabeled $(>80 \%)$. The isotopic steadystate level of $(m+6)$ mass fraction decreased as the ethanol fraction increased. This reflected a decrease of the ratio between the gluconate tracer uptake rate and the oxPPP flux. Using the method described by Zhao et al. (2008), the oxPPP fluxes were calculated (see Fig. 3) based on the dynamic mass isotopomer data in these experiments (the data obtained in the first hour). The oxPPP fluxes were found to be essentially constant among cultures grown on pure glucose, $15 \%$ ethanol and $48 \%$ ethanol. This flux satisfied more than $85 \%$ of the cytosolic NADPH demand (see Fig. 1).

Enzymatic activity analysis

The enzyme activity of ALDH in the glucose-limited culture was found to be negligible in $P$. chrysogenum (Harris et al. 2006). However, the ALDH activities with both cofactors $\left(\mathrm{NAD}^{+}\right.$and $\mathrm{NADP}^{+}$) were found in the crude cell extracts of the cultures grown on substrates mixed with ethanol $(0.15$ and $0.48 \mathrm{Cmol} / \mathrm{Cmol}$; see Fig. 4). These activities show that the cells are 


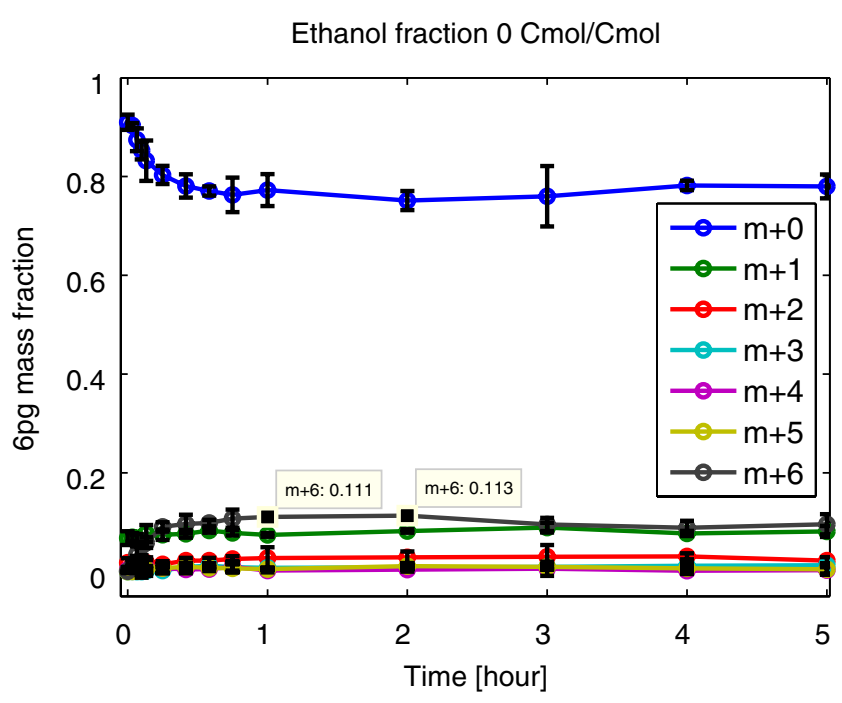

Ethanol fraction $0.15 \mathrm{Cmol} / \mathrm{Cmol}$

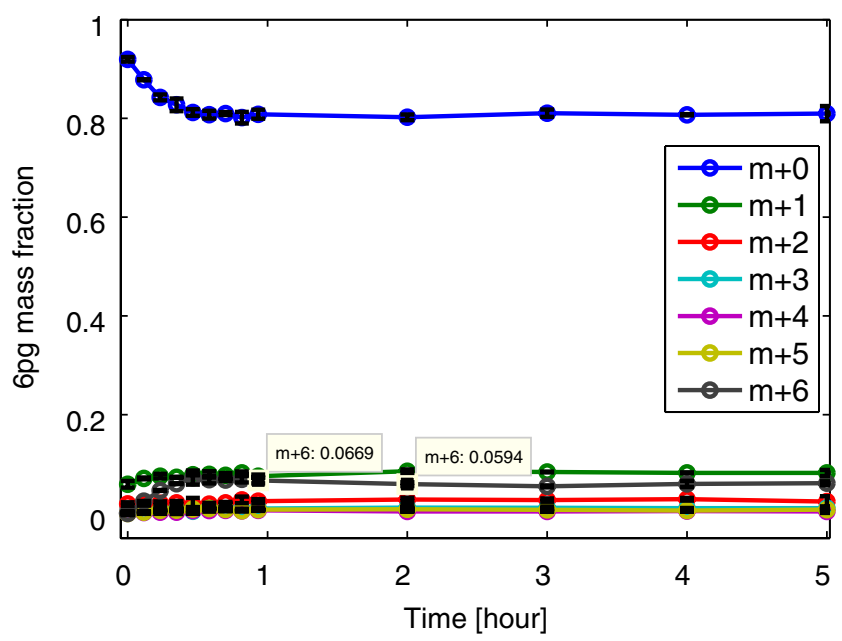

Ethanol fraction $0.48 \mathrm{Cmol} / \mathrm{Cmol}$

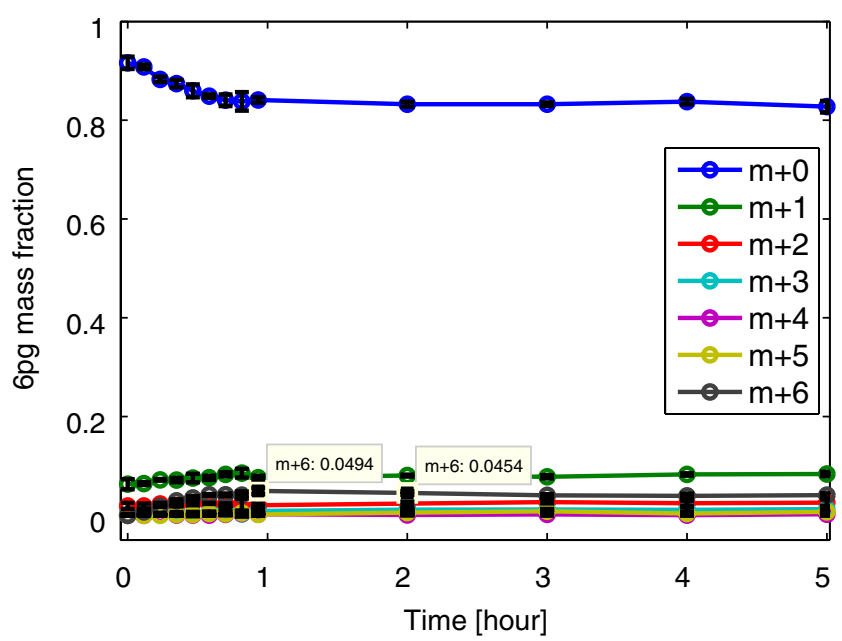

Fig. 2 Mass distribution of intracellular $6 \mathrm{pg}$ during the labeling experiment, error bar is the calculated $95 \%$ confidence interval

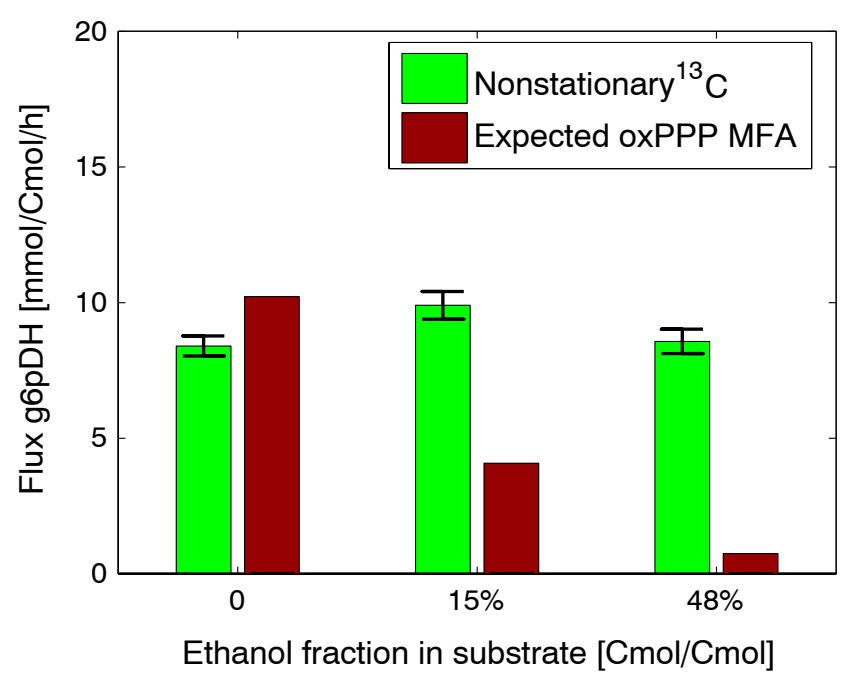

Fig. 3 Comparison between measured oxPPP flux using ${ }^{13} \mathrm{C}$ data and the expected oxPPP flux by MFA assuming a fully $\mathrm{NADP}^{+}$. dependent ALDH

already able to oxidize acetaldehyde into acetate at $0.15 \mathrm{Cmol} / \mathrm{Cmol}$ ethanol, with the help of either cofactor. Under the applied in vitro conditions, $\mathrm{NAD}^{+}$ was found to be slightly preferred over $\mathrm{NADP}^{+}$in both ethanol fractions. However, the preference was not significant. Note that the enzyme activity was expressed per unit amount of extracted protein. In both experiments ( $15 \%$ and $48 \%$ ethanol fraction), the extracted protein concentrations in the sample were $3.0 \mathrm{~g} / \mathrm{L}$, which means $15 \mathrm{mg}$ of extracted protein per sample because the sample volume was $5 \mathrm{~mL}$. Given that the biomass amount was approximately $60 \mathrm{mg}$, the extracted protein weight fraction in biomass was 0.25 .

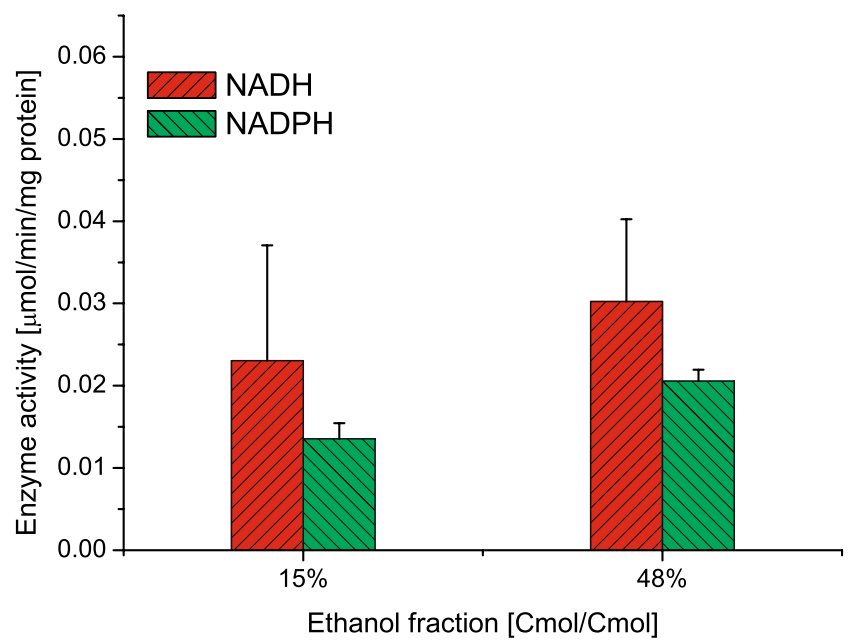

Fig. 4 Measured in vitro aldehyde dehydrogenase activity on different cofactors 


\section{Discussion}

Isotopic non-stationary gluconate tracer method

The isotopic non-stationary gluconate tracer method used is suitable for this study not only because of the short time frame needed and the independence of the assumptions such as reversibility and amino acid synthesis routes but also because it was shown that the precision of the determined oxPPP is higher when compared with methods using only labeled glucose (Kleijn et al. 2006). It is, however, important to be able to accurately quantify the gluconate uptake rate when using this approach, as the labeling data essentially delivered information on the ratio of the oxPPP and the gluconate uptake flux. To minimize the disturbance to the metabolism introduced by gluconate uptake, the ratio of the gluconate uptake rate to the glucose uptake rate was fixed at 1:19. Kleijn et al. (2006) showed that at this ratio, neither the extracellular rates such as growth rate and penicillin production rate nor the intracellular metabolite concentrations were changed. When the ethanol fraction in the substrate mixture increases beyond $48 \%$, accurate quantification of the gluconate uptake rate can become difficult, due to the diminishing glucose uptake rate and the fixed ratio of gluconate/glucose uptake. This method is therefore suitable only for the experiments with high glucose/gluconate uptake rates.

\section{Cytosolic NADPH balance}

The enzyme assays carried out by Harris et al. (2006) showed that cytosolic NADPH can only be produced by the oxPPP pathway and the isocitrate dehydrogenase (IDH), in a glucose-limited culture. In the metabolic model of P. chrysogenum (van Gulik et al. 2000), the ALDH reaction was assumed to produce cytosolic NADPH based on the knowledge of other fungi (Grabowska and Chelstowska 2003; Bruinenberg et al. 1983). In this assumption, the oxidation of acetaldehyde to acetate alone can provide sufficient NADPH for the cell when the ethanol uptake rate is greater than $21 \mathrm{mmol} / \mathrm{Cmol} / \mathrm{h}$. In order to keep the NADPH balance in the cytosol, the other major cytosolic NADPH producing flux oxPPP would have to be shut down (van Gulik et al. 2000; Kiefer et al. 2004; Kleijn et al. 2007). However, this hypothesis about NADPH production from ALDH (see Fig. 3: calculated oxPPP flux with $\mathrm{NADP}^{+}$-ALDH assumption) is clearly contradicted by the oxPPP flux determined based on our present ${ }^{13} \mathrm{C}$ flux analysis results. This result indicates that the cytosolic ALDH of P. chrysogenum is not $\mathrm{NADP}^{+}$de- pendent. Given the fact that both the cytosolic NADPH demand and NADPH production from the oxPPP are nearly constant in the studied ethanol fraction range, the ALDH contribution to the cytosolic NADPH must be negligible (for $15 \%$ and $48 \%$ ethanol).

It should be noted that the flux through the cytosolic $\mathrm{NADP}^{+}$-dependent isocitrate dehydrogenase $\left(\mathrm{NADP}^{+}-\mathrm{IDH}\right)$ is not constrained by the cytosolic NADPH balance. The $\mathrm{NADP}^{+}$-IDH flux is used to provide the carbon precursor for glutamate, glutamine, proline, and lysine. The production rates of these amino acids are determined by the growth rate and biomass composition. In our experiments, these rates were maintained constant. Therefore, the cytosolic $\mathrm{NADP}^{+}$-IDH flux is also fixed. This conclusion is consistent with the results of the experiments conducted by Bruinenberg et al. (1983), in which the oxPPP was then left as the only flux that has the flexibility to balance the cytosolic NADPH pool.

\section{Additional NADPH source}

Besides the cytosolic NADPH sources discussed above, malic enzyme activity is also a potential NADPH source and was found in filamentous fungi (Wynn and Ratledge 1997). In a related work, David et al. (2006) observed that many of the genes of the PP pathway are downregulated for Aspergillus nidulans grown on pure ethanol compared with a glucose culture. They suggested that malic enzyme would replace the role for NADPH supply of PP pathway in a pure ethanol culture. It should be noted that the PP pathway resides in cytosol, while the malic enzyme is known to exist either in mitochondria (in S. cerevisiae, Boles et al. 1998) or in peroxisome (in A. nidulans and P. chrysogenum, Kiel et al. 2009). A NADPH shuttle system, such as using IDH would be required. Recent research has shown that IDH can be found in both the cytosol (Harris et al. 2006) and peroxisome (Kiel et al. 2009) of $P$. chrysogenum. These findings suggest that it would be possible that the proposed NADPH shuttle is active. However, according to our ${ }^{13} \mathrm{C}$ flux analysis results, the oxPPP flux remained largely constant up to $48 \%$ ethanol. This indicates that, at least up to this fraction of ethanol, the oxPPP is still the major cytosolic NADPH source in $P$. chrysogenum rather than the malic enzyme. Recently, we analyzed the activity of the malic enzyme for $P$. chrysogenum culture grown in a ethanol-limited chemostat, according to the method described by Harris et al. (2006). No activity could be found beyond the detection limit. This further confirms that the role of malic enzyme in cytosolic NAPDH regeneration is 
very limited for $P$. chrysogenum, despite the fact that it is closely related to $A$. nidulans.

In vitro vs. in vivo aldehyde dehydrogenase activity

When the results of the calculated in vivo (after converting the unit from flux to activity) and the in vitro activities (see Fig. 4) are compared, it can be seen that the in vitro activities of both experiments $(15 \%$ and $48 \%$ ethanol of feed) were comparable or less than the in vivo flux, which were 0.021 and $0.072 \mu \mathrm{mol} / \mathrm{mg} / \mathrm{min}$, respectively (for the unit conversion from millimoles per $\mathrm{C}$ mole per hour to micromoles per milligram per minute, see the "Materials and methods" section). The main purpose of the in vitro aldehyde dehydrogenase activity assay was to show the cofactor specificity. Even though $\mathrm{NAD}^{+}$was found to be slightly preferred, it is worthwhile to note that the results were only valid qualitatively. Large uncertainties exist in the analysis of the assay with $\mathrm{NAD}^{+}$(see Fig. 4), compared with other enzyme assays for $P$. chrysogenum made by Harris et al. (2006). These uncertainties originated from the enzyme instability during sample storage and the assay. Nevertheless, the results were sufficient to show that the $\mathrm{NADP}^{+}$activity was not significantly higher than that of the $\mathrm{NAD}^{+}$.

From a thermodynamic point of view, under in vivo condition, the feasibility of the reaction is determined by the ratio of product and substrate, in this case the cytosolic $\mathrm{NAD}^{+} / \mathrm{NADH}$ and $\mathrm{NADP}^{+} / \mathrm{NADPH}$. Recently, Canelas et al. (2008) showed that direct measurements of the whole cell average concentrations of these cofactors will result in distorted estimations on their cytosolic ratios. This is mostly due to the presence of the protein-bound NADH (Bücher et al. 1972) and unknown distributions of these cofactors over the cytosolic and mitochondrial compartment. Therefore, those cytosolic cofactor ratios cannot be obtained from measurements of their cell averaged concentrations. From various studies using indicator reactions, it was shown that over a wide range of kingdoms, the ratio between cytosolic $\left(\mathrm{NAD}^{+} / \mathrm{NADH}\right)$ and $\left(\mathrm{NADP}^{+} / \mathrm{NADPH}\right)$ are in the order of 100 (Bautista et al. 1979; Satrustegui et al. 1983; Greenbaum et al. 1971; Canelas et al. 2008). These observations were further reinforced by the analysis results of Henry et al. (2007), who showed the thermodynamic feasible minimal ratio of $\mathrm{NAD}^{+} / \mathrm{NADH}$ and maximum ratio $\mathrm{NADP}^{+} / \mathrm{NADPH}$. Consequently, under in vivo conditions, the ALDH reaction proceeding with the $\mathrm{NAD}^{+}$ bares much greater thermodynamic driving force than its phosphorylated counterpart. This is in line with our findings in this study based on the ${ }^{13} \mathrm{C}$ flux analysis and cytosolic NADPH balance.

Some $\mathrm{NADP}^{+}$-dependent reactions can be reversed under certain physiological conditions, so that a normal NADPH producing reaction would be changed to NADPH-consuming reaction. As demonstrated by Yoo et al. (2008), this can happen to IDH when cofeeding glucose and glutamine. However, as the TCA cycle is running in positive direction in this study, it is unlikely that the IDH reaction can reverse. Therefore, the cytosolic NADPH balance discussed above should still hold.

Impact of ALDH cofactor change on the penicillin yield

As discussed above, the in vivo cytosolic ALDH in $P$. chrysogenum is found to be $\mathrm{NAD}^{+}$dependent. An $\mathrm{NADP}^{+}$-dependent ALDH would gradually reduce the need for oxPPP flux as the ethanol uptake flux increases. Genetically changing the cofactor dependency of ALDH to exclusive $\mathrm{NADP}^{+}$and cofeeding ethanol to the fermentation could thus result in higher penicillin production. This can be achieved by either protein engineering (Liang et al. 2007) or by the replacement of an ALDH with only $\mathrm{NADP}^{+}$dependency (Estey et al. 2007). As an example, for a defined growth rate $0.05 \mathrm{~h}^{-1}$ and a biomass-specific penicillin production rate of $0.5 \mathrm{mmol} / \mathrm{Cmol} / \mathrm{h}$, product yield on substrate

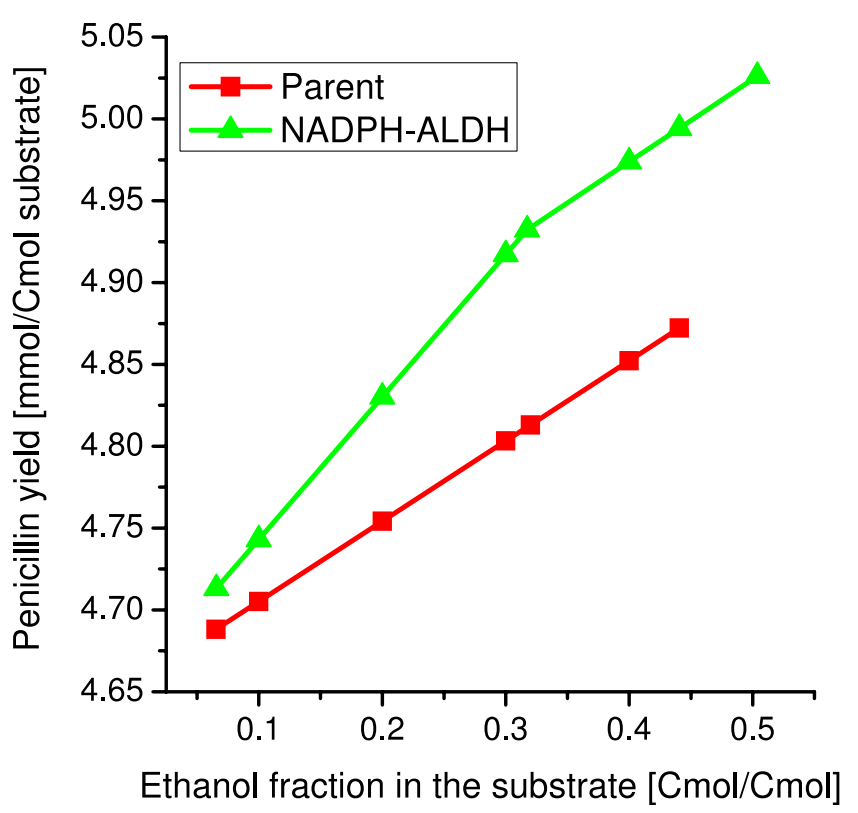

Fig. 5 Comparing the simulated yields of penicillin-G on the mixed substrate of $P$. chrysogenum with different cofactors of ALDH at different ethanol fractions 
can be compared for two different ALDH $\left(\mathrm{NAD}^{+}\right.$or $\mathrm{NADP}^{+}$) under different glucose/ethanol ratios (see Fig. 5). It is clear that modifying ALDH cofactor specificity would result in an increase of up to $2 \%$ in the penicillin yield on substrates. However, this can only benefit the overall economics of penicillin production when ethanol price drops closer to glucose.

Acknowledgements This project is financially supported by the Netherlands Ministry of Economic Affairs and the B-Basic partner organizations (www.b-basic.nl) through B-Basic, a publicprivate NWO-ACTS programme $($ ACTS = Advanced Chemical Technologies for Sustainability). Grateful acknowledgement to Diana van der Graaf-Harris and Marijke Luttik were for their help on the enzymatic activity analysis of aldehyde dehydrogenase and malic enzyme and to Cor Ras for his analysis of the mass isotopomer samples.

Open Access This article is distributed under the terms of the Creative Commons Attribution Noncommercial License which permits any noncommercial use, distribution, and reproduction in any medium, provided the original author(s) and source are credited.

\section{References}

Baich A (1971) The biosynthesis of proline in Escherichia coli: phosphate-dependent glutamate-semialdehyde dehydrogenase (NADP), the second enzyme in the pathway. Biochim Biophys Acta 244(1):129-134

Bautista J, Satrústegui J, Machado A (1979) Evidence suggesting that the NADPH/NADP ratio modulates the splitting of the isocitrate flux between the glyoxylic and tricarboxylic acid cycles, in Escherichia coli. FEBS Lett 105(2):333-336

Blombach B, Schreiner ME, Bartek T, Oldiges M, Eikmanns BJ (2008) Corynebacterium glutamicum tailored for highyield L-valine production. Appl Microbiol Biotechnol 79(3): 471-479

Boles E, de Jong-Gubbels P, Pronk JT (1998) Identification and characterization of mae1, the Saccharomyces cerevisiae structural gene encoding mitochondrial malic enzyme. J Bacteriol 180(11):2875-2882

Bro C, Regenberg B, Nielsen J (2004) Genome-wide transcriptional response of a Saccharomyces cerevisiae strain with an altered redox metabolism. Biotechnol Bioeng 85(3):269-276. doi:10.1002/bit.10899

Bruinenberg PM, van Dijken JP, Scheffers WA (1983) An enzymic analysis of NADPH production and consumption in Candida utilis. J Gen Microbiol 129(4):965-971

Bücher T, Brauser B, Conze A, Klein F, Langguth O, Sies H (1972) State of oxidation-reduction and state of binding in the cytosolic NADH-system as disclosed by equilibration with extracellular lactate-pyruvate in hemoglobin-free perfused rat liver. Eur J Biochem 27(2):301-317

Canelas AB, van Gulik WM, Heijnen JJ (2008) Determination of the cytosolic free NAD/NADH ratio in Saccharomyces cerevisiae under steady-state and highly dynamic conditions. Biotechnol Bioeng 100(4):734-743

Casqueiro J, Gutiérrez S, Bañuelos O, Fierro F, Velasco J, Martín JF (1998) Characterization of the lys2 gene of Penicillium chrysogenum encoding $\alpha$-aminoadipic acid reductase. Mol Gen Genet 259(5):549-556
Creaser EH, Varela-Torres R (1971) Immunological comparisons of histidinol dehydrogenases. J Gen Microbiol 67(1):85-90

David H, Hofmann G, Oliveira AP, Jarmer H, Nielsen J (2006) Metabolic network driven analysis of genome-wide transcription data from Aspergillus nidulans. Genome Biol 7(11):R108

Díez B, Mellado E, Rodríguez M, Bernasconi E, Barredo JL (1999) The NADP-dependent glutamate dehydrogenase gene from Penicillium chrysogenum and the construction of expression vectors for filamentous fungi. Appl Microbiol Biotechnol 52(2):196-207

Duncan K, Edwards RM, Coggins JR (1988) The Saccharomyces cerevisiae ARO1 gene. An example of the co-ordinate regulation of five enzymes on a single biosynthetic pathway. FEBS Lett 241(1-2):83-88

Esmahan C, Alvarez E, Montenegro E, Martin JF (1994) Catabolism of lysine in Penicillium chrysogenum leads to formation of 2-aminoadipic acid, a precursor of penicillin biosynthesis. Appl Environ Microbiol 60(6):17051710

Estey T, Piatigorsky J, Lassen N, Vasiliou V (2007) ALDH3A1: a corneal crystallin with diverse functions. Exp Eye Res 84(1):3-12. doi:10.1016/j.exer.2006.04.010

Evers ME, Trip H, van den Berg MA, Bovenberg RAL, Driessen AJM (2004) Compartmentalization and transport in $\beta$ lactam antibiotics biosynthesis. Adv Biochem Eng Biotechnol 88:111-135

Georgi T, Rittmann D, Wendisch VF (2005) Lysine and glutamate production by Corynebacterium glutamicum on glucose, fructose and sucrose: roles of malic enzyme and fructose-1,6-bisphosphatase. Metab Eng 7(4):291-301. doi:10.1016/j.ymben.2005.05.001

Grabowska D, Chelstowska A (2003) The ALD6 gene product is indispensable for providing NADPH in yeast cells lacking glucose-6-phosphate dehydrogenase activity. J Biol Chem 278(16):13,984-13,988. doi:10.1074/jbc.M210076200

Greenbaum AL, Gumaa KA, McLean P (1971) The distribution of hepatic metabolites and the control of the pathways of carbohydrate metabolism in animals of different dietary and hormonal status. Arch Biochem Biophys 143(2): $617-663$

Harris DM, Diderich JA, van der Krogt ZA, Luttik MAH, Raamsdonk LM, Bovenberg RAL, van Gulik WM, van Dijken JP, Pronk JT (2006) Enzymic analysis of NADPH metabolism in $\beta$-lactam-producing Penicillium chrysogenum: presence of a mitochondrial NADPH dehydrogenase. Metab Eng 8(2):91-101

Henriksen CM, Christensen LH, Nielsen J, Villadsen J (1996) Growth energetics and metabolic fluxes in continuous cultures of Penicillium chrysogenum. J Biotechnol 45(2): $149-164$

Henry CS, Broadbelt LJ, Hatzimanikatis V (2007) Thermodynamics-based metabolic flux analysis. Biophys J 92(5):1792-1805. doi:10.1529/biophysj.106.093138

Hijarrubia MJ, Aparicio JF, Casqueiro J, Martín JF (2001) Characterization of the lys 2 gene of Acremonium chrysogenum encoding a functional alpha-aminoadipate activating and reducing enzyme. Mol Gen Genet 264(6):755-762

Jones EE, Broquist HP (1966) Saccharopine, an intermediate of the aminoadipic acid pathway of lysine biosynthesis. 3. Aminoadipic semialdehyde-glutamate reductase. J Biol Chem 241(14):3430-3434

Kabus A, Georgi T, Wendisch VF, Bott M (2007) Expression of the Escherichia coli pntAB genes encoding a membranebound transhydrogenase in Corynebacterium glutamicum 
improves L-lysine formation. Appl Microbiol Biotechnol 75(1):47-53

Kiefer P, Heinzle E, Zelder O, Wittmann C (2004) Comparative metabolic flux analysis of lysine-producing Corynebacterium glutamicum cultured on glucose or fructose. Appl Environ Microbiol 70(1):229-239

Kiel JAKW, van den Berg MA, Fusetti F, Poolman B, Bovenberg RAL, Veenhuis M, van der Klei IJ (2009) Matching the proteome to the genome: the microbody of penicillinproducing Penicillium chrysogenum cells. Funct Integr Genomics 9(2):167-184

Kleijn RJ, van Winden WA, Ras C, van Gulik WM, Schipper D, Heijnen JJ (2006) ${ }^{13} \mathrm{C}$-labeled gluconate tracing as a direct and accurate method for determining the pentose phosphate pathway split ratio in Penicillium chrysogenum. Appl Environ Microbiol 72(7):4743-4754

Kleijn RJ, Liu F, van Winden WA, van Gulik WM, Ras C, Heijnen JJ (2007) Cytosolic NADPH metabolism in penicillin-G producing and non-producing chemostat cultures of Penicillium chrysogenum. Metab Eng 9:112-123

Lee HS, Hwang BJ (2003) Methionine biosynthesis and its regulation in Corynebacterium glutamicum: parallel pathways of transsulfuration and direct sulfhydrylation. Appl Microbiol Biotechnol 62(5-6):459-467

Liang L, Zhang J, Lin Z (2007) Altering coenzyme specificity of Pichia stipitis xylose reductase by the semi-rational approach CASTing. Microb Cell Fact 6:36. doi:10.1186/14752859-6-36

Lowry OH, Rosebrough NJ, Farr AL, Randall RJ (1951) Protein measurement with the folin phenol reagent. J Biol Chem 193(1):265-275

Minard KI, McAlister-Henn L (2005) Sources of NADPH in yeast vary with carbon source. J Biol Chem 280(48):39,89039,896. doi:10.1074/jbc.M509461200

Nasution U, van Gulik WM, Ras C, Proell A, Heijnen JJ (2008) A metabolome study of the steady-state relation between central metabolism, amino acid biosynthesis and penicillin production in Penicillium chrysogenum. Metab Eng 10(1): $10-23$

Qureshi AA, Beytia E, Porter JW (1973) Squalene synthetase. II. Purification and properties of bakers' yeast enzyme. J Biol Chem 248(5):1848-1855

Qureshi N, Dugan RE, Cleland WW, Porter JW (1976) Kinetic analysis of the individual reductive steps catalyzed by $\beta$-hydroxy- $\beta$-methylglutaryl-coenzyme a reductase obtained from yeast. Biochemistry 15(19):4191-4107

Robichon-Szulmajster H, Surdin Y, Mortimer RK (1966) Genetic and biochemical studies of genes controlling the synthesis of threonine and methionine in Saccharomyces. Genetics 53(3):609-619

Rossi JJ, Vender J, Berg CM, Coleman WH (1977) Partial purification and some properties of delta1-pyrroline5-carboxylate reductase from Escherichia coli. J Bacteriol 129(1):108-114

Satrustegui J, Bautista J, Machado A (1983) NADPH/NADP ${ }^{+}$ ratio: regulatory implications in yeast glyoxylic acid cycle. Mol Cell Biochem 51(2):123-127

Stepansky A, Leustek T (2006) Histidine biosynthesis in plants. Amino Acids 30(2):127-142. doi:10.1007/s00726-005-0247-0

Thykaer J, Nielsen J (2003) Metabolic engineering of $\beta$-lactam production. Metab Eng 5(1):56-69
Thykaer J, Rueksomtawin K, Noorman H, Nielsen J (2008) NADPH-dependent glutamate dehydrogenase in Penicillium chrysogenum is involved in regulation of beta-lactam production. Microbiol 154(Pt 4):1242-1250. doi:10.1099/ mic.0.2007/010017-0

Tomenchok DM, Brandriss MC (1987) Gene-enzyme relationships in the proline biosynthetic pathway of Saccharomyces cerevisiae. J Bacteriol 169(12):5364-5372

van den Berg MA, Albang R, Albermann K, Badger JH, Daran JM, Driessen AJM, Garcia-Estrada C, Fedorova ND, Harris DM, Heijne WHM, Joardar V, Kiel JAKW, Kovalchuk A, Martín JF, Nierman WC, Nijland JG, Pronk JT, Roubos JA, van der Klei IJ, van Peij NNME, Veenhuis M, von Döhren H, Wagner C, Wortman J, Bovenberg RAL (2008) Genome sequencing and analysis of the filamentous fungus Penicillium chrysogenum. Nat Biotechnol 26(10):1161-1168

van Gulik WM, de Laat W, Vinke JL, Heijnen JJ (2000) Application of metabolic flux analysis for the identification of metabolic bottlenecks in the biosynthesis of penicillin-G. Biotechnol Bioeng 68(6):602-618

van der Heijden RTJM, Heijnen JJ, Hellinga C, Romein B, Luyben KCAM (1994) Linear constraint relations in biochemical reaction systems: I. Classification of the calculability and the balanceability of conversion rates. Biotechnol Bioeng 43:3-10

van Winden WA, van Dam JC, Ras C, Kleijn RJ, Vinke JL, van Gulik WM, Heijnen JJ (2005) Metabolic-flux analysis of Saccharomyces cerevisiae CEN. PK113-7D based on mass isotopomer measurements of ${ }^{13} \mathrm{C}$-labeled primary metabolites. FEMS Yeast Res 5(6-7):559-68

Wakil SJ, Stoops JK, Joshi VC (1983) Fatty acid synthesis and its regulation. Annu Rev Biochem 52:537-579. doi:10.1146/ annurev.bi.52.070183.002541

Wittmann C, Heinzle E (2002) Genealogy profiling through strain improvement by using metabolic network analysis: metabolic flux genealogy of several generations of lysineproducing corynebacteria. Appl Environ Microbiol 68(12): $5843-5859$

Wynn J, Ratledge C (1997) Malic enzyme is a major source of NADPH for lipid accumulation by Aspergillus nidulans. Microbiology 143(1):253-257

Yamaki H, Yamaguchi M, Imamura H, Suzuki H, Nishimura T, Saito H, Yamaguchi H (1990) The mechanism of antifungal action of (S)-2-amino-4-oxo-5-hydroxypentanoic acid, RI-331: the inhibition of homoserine dehydrogenase in Saccharomyces cerevisiae. Biochem Biophys Res Commun 168(2):837-843

Yoo H, Antoniewicz MR, Stephanopoulos G, Kelleher JK (2008) Quantifying reductive carboxylation flux of glutamine to lipid in a brown adipocyte cell line. J Biol Chem 283(30):20,621-20,627

Yoshimoto A, Sato R (1968) Studies on yeast sulfite reductase. I. Purification and characterization. Biochim Biophys Acta 153(3):555-575

Zabriskie TM, Jackson MD (2000) Lysine biosynthesis and metabolism in fungi. Nat Prod Rep 17(1):85-97

Zhao Z, Kuijvenhoven K, Ras C, van Gulik WM, Heijnen JJ, Verheijen PJT, van Winden WA (2008) Isotopic nonstationary ${ }^{13} \mathrm{C}$ gluconate tracer method for accurate determination of the pentose phosphate pathway split-ratio in Penicillium chrysogenum. Metab Eng 10(3-4):178-186 